\title{
Ten Years Gone, Holdin on, Ten Years Gone: The Circular Economy and the Evolutionary Trajectory of the Competitive Intelligence Profession
}

\author{
John J Mc Gonagle* \\ Department of Intelligence, USA
}

*Corresponding author: John J Mc Gonagle, Department of Intelligence, USA.

Received Date: January 05, 2019

Published Date: January 28, 2019

\section{Rise of the Circular Economy}

\section{What is it?}

The underlying premise of the Circular Economy (CE) is that businesses face major challenges: grow and create value while dealing with anticipated volatilities in and shortages of necessary natural resources. CE advocates contend that, due to environmental concerns, this challenge is being made much more difficult. They see increases in both prices business pay and uncertainty in operation.

There are as many definitions of $\mathrm{CE}$ as there are advocates

"The underlying assumption [of $\mathrm{CE}$ ] is that the dominant global economic system, focused on continuous economic growth, unlimited levels of consumption, and minimal regulation needs to change."

"Today's linear economy-in which, quite simply, natural resources are extracted from the ground, made into products, used, and thrown away-was highly successful in delivering economic development during the 20th century. However, global trends indicate that the traditional, linear model's ability to produce economic growth is being increasingly challenged, prompting a search for alternative approaches that can work in the long term."

"The $[\mathrm{CE}]$... is restorative and regenerative by design and aims to keep products, components, and materials at their highest utility and value at all times, distinguishing between technical and biological cycles. This new economic model seeks to ultimately decouple global economic development from finite resource consumption."

"[CE] is a system geared toward designing out waste; it looks at all options across the entire chain in order to use as few resources as possible in the first place, keep those resources in circulation for as long as possible, extract as much value from those resources, and then recover and regenerate those materials and products at the end of that particular useful life [1-5]."

Regardless of the precise definition, there is, among its advocates, relative unanimity about its perceived positive impacts: $\mathrm{CE}$ is a solution to create "sustainable development and business innovation". "[CE] is gaining increasing attention in Europe and around the world as a potential way for our society to increase prosperity, while reducing dependence on primary materials and energy." CE "provides the key to managing this challenge at both the macro and micro level, allowing economic development within natural resource limits and allowing companies to innovate to enable customers and users to do 'more with less."'

"According to the research documented in 'Finding growth within: A new framework for Europe,' a [CE] could generate a net economic gain of €1.8 trillion per year by $2030 . "$

"The principal benefits to moving to the [CE] are as follows:

- Substantial net material savings and reduced exposure to price volatility: ...

- Increased innovation and job creation potential: ...

- Increased resilience in living systems and in the economy: ..."

"Instead of focusing on large inventories of homogenous goods shipped and sold at central locations, a business model can be created, for example, that focuses on the customer and the products' use."

"[CE] enables key policy objectives such as generating economic growth, creating jobs, and reducing environmental impacts, including carbon emissions." 
It might appear that $\mathrm{CE}$ is only a theoretical approach to moving toward a more environmentally-sensitive, sustainable economy. In fact, some CE advocates see it as a way to "buy time" to make needed environmental corrections. But CE is that and much more. It impacts the entire supply chain. "Companies no longer focus mainly on driving more volume and squeezing out cost through greater efficiency in supply chains, factories and operations. Rather, [in $\mathrm{CE}]$ they concentrate on rethinking products and services from the bottom up to 'future proof' their operations to prepare for inevitable resource constraints - all the way through to the customer value proposition."

$\mathrm{CE}$, as an economic approach, has already gathered widespread private and public sector support. Some key business supporters/ drivers of CE include familiar global names: Vodafone, Cisco, Danone, Nike, Philips, Renault, Unilever, Google, Dow, MGM Resorts International, Republic Services, Sealed Air, and Shell. In the nonprofit and consulting sectors, CE's drivers include the MacArthur Foundation, European Commission, McKinsey, U.S. Chamber of Commerce, The Club of Rome, and Accenture [5-10].

\section{What does CE do?}

When applied, CE will generate, require, or force profound changes in business structure and operation. Take for example, one business' actions:

"Long a pioneer of circular practices and on a mission to achieve its goal of zero negative impact, [the company] created a network of circular business partners. From return chain sourcing to more sustainable installation practices, it relies on its network of circular economy business partners to help drive innovation and jointly develop new solutions to deliver on [its] zero negative impact aspiration." This paper's contention is that CE will cause profound changes in competitive and strategic intelligence (CI) [11-15].

\section{Is CE coming?}

CU is not merely a theory. CE is already being adopted, and adoption is expanding. For example, in 2012, the European Commission issued its CE-oriented "Manifesto for a ResourceEfficient Europe" calling for

"[i]mplementing, using and adopting smart regulation, standards and codes of conduct that a) create a level playing-field, b) reward front-runners and c) accelerate the transition, and d) take into account the social and international implications of our actions."

That EU process continues: "the European Circular Economy Stakeholder Platform" is to be announced at the "Circular Economy Stakeholder Conference" in March 2017. With such interest and support, CE will certainly continue to be viewed positively by companies, NGOs, and governments intimately concerned with environmental issues. For example, a scholar recently noted that the CE "is becoming increasingly important for business. The 2013 UN Global Compact/Accenture CEOs triennial sustainability survey found that although the CE was almost entirely absent from their conversations in 2010, the concept had quickly taken hold among CEOs focused on innovation and the potential of new business models. Already, a third of CEOs in the 2013 survey report that they are actively seeking to employ CE models [15-20]."

Also, emerging long-term economic and political trends, including pressures to reduce trade balances, shift from multilateral to bilateral trade, revise business taxes, and develop "national" economic capabilities may have major structural and operational impacts. One would be that local, national, and global businesses must review and restructure existing supply chains. A review of all options will necessarily include considering CE. This paper now highlights what CE could mean to the future of the private sector CI profession over the next decade utilizing what its users and supporters have said and observed:

\section{Impacts of $\mathrm{CE}$ on $\mathrm{CI}$}

\section{At the macro level}

Circular economy: "Building a strong foundation for [CE] requires coordinated action. Shifting to a circular economic model [in Europe] will affect all sectors and policy domains. Here are [two of the] four priorities: ...

a) Create initiatives at the European, national, and city levels to facilitate the development of profitable circular business opportunities at scale.

b) Design a new governance system to steer the economy toward greater resource productivity, employment, and competitiveness."

"Many [CE] opportunities have a sound underlying profitability, but there are often non-financial barriers limiting further scaleup or holding back development pace. Policymakers can play an important role in helping businesses overcome these barriers.

"Barriers include unintended consequences of existing regulations (e.g. definitions of waste that hinder trade and transport of products for remanufacturing), social factors such as a lack of experience among companies and policymakers to detect and capture [CE] opportunities, and market failures such as imperfect information (e.g. for businesses to repair, disassemble and remanufacture products) and unaccounted externalities (e.g. carbon emissions)." "[CE] requires not only concentrating on a narrow definition of the core business, but also participating in collaborative circular networks...engaging suppliers, manufacturers, retailers, service suppliers and customers [20-25]."

\section{Impacts}

i. A firm's operations may be more transparent to competitors through reducing "imperfect information" and expanded collaboration.

ii. Acceptance of CI activities may be diminished under a "new governance system" that focuses more on "coordinated action" rather than on competition.

\section{Management}

\section{Circular economy}

"Every aspect of management will be impacted by the [CE] including; engaging with suppliers so that they are prepared to 
identify the components they source and are willing to switch where necessary to sustainable ones; managing the internal and outsourced innovation needed; marketing CE and potentially learning reselling techniques; servitization; reverse logistics; motivating and reskilling employees; and embedding strategy so that the transformation is real and not superficial, leaving the organisation open to charges of greenwashing.

"Managing the CE will require additional skills to understand the basic science relevant to your industry; to learn how to collaborate and partner (sometimes with unusual and unexpected partners such as NGOs, development agencies or academic institutions); and how to enthuse employees that CE is a positive business transformation which they want to contribute to, and not just the latest management fad [25-30]."

\section{Impacts}

a. Suppliers will become more "transparent" and thus easier CI targets.

b. CI staff must learn to "understand the basic science relevant" to more than just their firm.

c. Businesses partnering with "unusual and unexpected" partners will generate new potential targets for competitors' CI actions.

\section{Transparency}

\section{Circular economy}

"[CE will establish] higher labor and environmental standards for suppliers and set up mechanisms to make supply chains more transparent. For example, the software company EVRYTHNG and packaging maker Avery Dennison have together launched an effort to tag clothing so consumers can trace how individual items were produced all along the supply chain." "Inadequate business-tobusiness information on what resources a product contains and how it can be repaired or recycled is hindering resource efficiency. To tackle this barrier, the possible use of a 'product passport'... should be explored that would make such information easily accessible and applicable to the supply chain, thus facilitating efficient material flows and encouraging the creation of value in the circular economy."

\section{Impacts}

I. Transparency for consumers means increased access by competitors to your competitively sensitive data (CSD) and by you to theirs.

II. A product passport could make reverse engineering of products and packaging much easier for you - and for your competitors - to do.

\section{Manufacturing and Sourcing}

\section{Circular economy}

"[Companies operating in CE must] make sure that production is not only efficient, but that no resources are lost during the process and that the company can significantly scale up and maintain sourcing volumes from return chains. The latter often means shifting from large-scale sourcing from few suppliers to sourcing from many, heterogeneous and small-scale sources."

"[C]ompanies outside traditional industry sets can be crucial sources of talent, resources and digital technology, enabling infrastructures for new disruptive services founded on innovation and technology."

"Circular activities can, and will need to, grow from different parts of the company.... What is critical for success is for companies to develop cross-functional collaborations that link design, marketing, manufacturing, and recovery. Also, new expertise might be required, for example in materials science, logistics, and customer relationship management [30-34]."

"How big are the inefficiencies in the circular value chain? Combine that with a view of whether your competitors have begun to move toward circular and you build an understanding from which your company's journey can be shaped." "Enablers to improve cross-cycle and cross-sector performance are factors that support the required changes at a systems level and include ... education, both to increase general awareness and to create the skill base to drive circular innovation."

\section{Impacts}

a. Changing the number of suppliers can make accessing CSD more difficult but more valuable once accessed.

b. The skills and expertise required to provide CI will increase, adding training on unfamiliar technology and processes.

\section{Sales and Marketing}

\section{Circular economy}

"In [CE], sales and marketing is all about deepening the understanding of the use phase of products and feeding back revealed preferences from the markets so that products and services can be adapted for circular use."

\section{Impact}

Organizationally, CI may have reduced profiles when compared with marketing and market research which will have broader mandates under CE.

\section{Small Businesses}

\section{Circular economy}

"Companies with significant market share and capabilities along several vertical steps of the linear value chain could play a major role in [CE] innovation and driving circularity into the mainstream by leveraging their scale and vertical integration." "Value chains will converge and in some industries traditional upstream and downstream activities will merge. In others customers will become significantly more powerful, more mobile and more demanding."

\section{Impact}

- Smaller and medium-sized enterprises, and other CE outsiders, may need additional CI due to their exclusion from the core of CE. 
- Conversely, SMEs and other outsiders may find that their CSD is more protected than is that of their large competitors.

\section{New Partnerships and Sharing}

\section{Circular economy}

CE will require "collaborating networks from civil society, from research and policy communities, from business, from faith groups, from cultural groups, and from new economics practitioners." The Closed Loop Fund is a "social impact investment fund" involved with "best in class, replicable [CE] recycling models." It includes 3M, Coca-Cola, Colgate-Palmolive, Goldman Sachs, Johnson \& Johnson Family of Consumer Companies, Keurig Green Mountain, PepsiCo, PepsiCo Foundation, Procter \& Gamble, Unilever, Walmart, and the Walmart Foundation.

"Pioneer Products collected icing buckets used in Walmart store delis and difficult-to-recycle mixed plastics via an already existing reverse logistics network and used the resulting resin to manufacture 45-gallon trash cans that are sold on Walmart shelves. During 2014, more than 215,000 icing buckets were recycled into more than 351,000 trash cans. The plastic resin contributed $10.9 \%$ of the trash-can makeup, and $95 \%$ of the icing bucket was able to be reused in the new product."

\section{Impacts}

- The more institutions and groups share CSD with each other and with the government, the harder it is to protect, but the easier it is for CI professionals to collect on competitors.

- CE can make suppliers into closer partners, which can then become potential competitors.

\section{Projections}

The rise of the CE will necessarily have major impacts on competitive and strategic intelligence. They appear to fall into 4 broad categories:

- A change in the stature of CI.

- A reduction in employment opportunities with firms in the $\mathrm{CE}$, while increasing it in firms outside of the CE.

- Greater opportunities for those trained in defensive intelligence.

- A need for new skills and education for intelligence personnel working in the CE.

\section{First, the CE may change the stature of $\mathrm{CI}$ :}

- The general acceptance of CI activities may diminish under any "new governance system" for CE that focuses on "coordinated action", rather than on competition. Without competition, there is no need for competitive intelligence.

- $\quad$ Organizationally, CI may have a reduce profile internally compared with marketing and market research with broader mandates due to the need to change approaches to consumers.
Second, for a firm in the CE, it will be easier to collect some competitors' CSD, making $\mathrm{CI}$ less valuable, reducing employment opportunities in CE firms, but increasing them in firms outside of the CE:

- $\quad$ More institutions and groups sharing CSD with each other and with the government makes it easier to access it. For example, suppliers becoming more transparent will be softer CI targets.

- Your competitors' operations will be more transparent to you due to the identification of "opportunities" or elimination of "imperfect information". For example, the rise of the product passport should make reverse engineering of products and packaging much easier.

- $\quad$ Transparency to consumers means increased access to your competitors' CSD for your CI personnel.

- $\quad$ Smaller and medium-sized enterprises, and other CE outsiders, may need more $\mathrm{CI}$ personnel due to their exclusion from some data sharing within the CE. SMEs and other outsiders may find that their CSD is more protected that is that of their large competitors in the CE.

Third, for a firm in the CE, it will be harder for $\mathrm{CI}$ personnel to protect their own CSD, which may cause a greater demand for CI personnel already skilled in defensive intelligence activities:

- $\quad$ More sharing of your CSD makes it easier for competitors to access it.

- Your firm's operations will be more transparent to competitors due to the identification of "opportunities" or elimination of "imperfect information".

- Transparency to consumers means increased access by your competitors to your CSD.

Fourth, new skills and continuing education will be needed by the surviving CI professionals:

- Intelligence personnel must learn to "understand the basic science relevant" to more than just their firm.

- Businesses in the CE partnering with "unusual and unexpected" partners will generate new potential targets for CI personnel, but they may be more difficult to penetrate.

- $\quad$ CI necessarily focuses more on suppliers, since in the CE can make suppliers into closer partners, and then quickly into potential competitors.

\section{Acknowledgement}

None.

\section{Conflict of Interest}

No conflict of interest. 


\section{References}

1. Ten Years Gone (1975) Led Zeppelin

2. Accenture Strategy (2014) Circular Advantage - Innovative Business Models and Technologies to Create Value in a World without Limits to Growth 2.

3. Hunter Lovins, Anders Wijkman, John Fullerton, Stewart Wallis, Graeme Maxton (2016) A Finer Future is Possible - How humanity can avoid system collapse and craft a better economic system.

4. Jennifer Gerholdt (2015) Going in Circles: How the Private Sector Is Leading the Circular Economy Revolution", U. S. Chamber of Commerce, Corporate Citizenship Center, Achieving a Circular Economy: How the Private Sector is Reimaging the Future of Business.

5. Ellen MacArthur Foundation (2015) Delivering the Circular Economy -A Toolkit for Policymakers.

6. Ellen MacArthur Foundation (2015) Deutsche Post Foundation, and McKinsey Center for Business and Environment, Growth Within: A Circular Economy Vision for A Competitive Europe.

7. Michael Søgaard Jørgensen (2015) Circular economy Possibilities and limitations as strategy for sustainable development and business innovation. UFRJ - 20 July 2015, Center for Design, Innovation and Sustainable Transition (DIST), Department of Development and Planning, Aalborg University Copenhagen.

8. Ellen MacArthur Foundation (2015) Deutsche Post Foundation, and McKinsey Center for Business and Environment, Growth Within: A Circular Economy Vision for A Competitive Europe.

9. McKinsey (2016) Center for Business and Environment, the circular economy: Moving from theory to practice, Special edition.

10. Ellen MacArthur Foundation (2015) Delivering the Circular Economy A Toolkit for Policymakers: 23-24.

11. Ellen MacArthur Foundation (2015) Delivering the Circular Economy A Toolkit for Policymakers: 19.

12. Timmermans, US Chamber of Commerce Foundation, Circular Economy". Ellen MacArthur Foundation, Partners, For a broader list, Circular Economy 100 members. This group includes businesses, government, cities, academic institutions, emerging innovators and affiliates.

13. Ellen MacArthur Foundation, Building Blocks of a Circular Economy, European Commission; McKinsey, op.cit.; US Chamber, op.cit.; Lovins, op.cit.; Accenture Strategy, op.cit.

14. European Commission Memo - Manifesto for a Resource-Efficient Europe (2012) European Commission, Agenda.
15. David Grayson (2015) Are we seeing the rise of a disruptive new business model. Management Focus 38: 12-15.

16. Morten Rossé Martin Stuchtey, Helga Vanthournout, How the circular economy could promote clean growth. in McKinsey op. cit. at 8. See also Accenture Strategy, op. cit., at 20.

17. Ellen MacArthur Foundation (2015) Delivering the Circular Economy A Toolkit for Policymakers.

18. Accenture Strategy, op. cit., at 18.

19. Grayson, op. cit., at 15-16.

20. Nathalie Remy, Eveline Speelman, Steven Swartz, Style that's sustainable: A new fast-fashion formula.

21. European Commission (2012) European Resource Efficiency Platform (EREP) - Manifesto and Policy Recommendations", Brussels: 7

22. Accenture Strategy, op. cit., at 18

23. Kris Timmermans (2016) Gaining A Competitive Edge through Today's Circular Economy.

24. Stuchtey, Martin (2013) Questions and Answers on the Circular Economy.

25. Accenture Strategy, op. cit., at 22.

26. Ellen MacArthur Foundation (2013) Towards the Circular Economy Vol. 2: opportunities for the consumer goods sector.

27. Accenture Strategy, op. cit., at 18.

28. Ellen MacArthur Foundation, Building Blocks of a Circular Economy.

29. Accenture Strategy (2015) Michael Søgaard Jørgensen, Circular economy Possibilities and limitations as strategy for sustainable development and business innovation UFRJ - 20 July 2015",

30. Center for Design, Innovation and Sustainable Transition (DIST), Department of Development and Planning, Aalborg University Copenhagen, , slide 42 noting the need for Analyses of competitors' environmental strategies".

31. European Commission (2012) European Commission Memo Manifesto for a Resource-Efficient Europe, Brussels, 17 December 2012 [MEMO/12/989], recognizing the need to bring in SMEs.

32. Bridget Croke, Enabling Conditions, Financing and Influence, USA

33. Fred Bedore Senior Director and Anna Vinogradova Walmart Is Closing the Loop", US Chamber, op. cit., at 68.

34. Neil Hawkins, advancing a Circular Economy Starts with Collaboration and It Starts Now, USA. 